\title{
HOMICÍDIOS E DESIGUALDADES SOCIAIS NA CIDADE DE SÃO PAULO: UMA VISÃO EPIDEMIOLÓGICA
}

\author{
Marcos Drumond Júnior*
}

\begin{abstract}
RESUMO: Este artigo tem como objetivo descrever e discutir a epidemiologia dos homicidios na cidade de São Paulo, com ênfase nas suas desigualdades sociais, a partir dos dados e da experiência do Programa de Aprimoramento das Informações de Mortalidade do Município de São Paulo (PRO-AIM). Os resultados mostram que os homicidios têm apresentado importância, dimensão e tendência crescente na cidade de São Paulo, apontando uma grande desigualdade social em todas estas características analisadas, segundo diferentes informações contidas nas declarações de óbito. A distribuição espacial mostra que os indices são maiores em regiöes da periferia e do centro velho da cidade. Os diferenciais foram também analisados no interior de um distrito de boas condições sociais. Discute-se algumas propostas de prevenção e controle dos homicidios com ênfase num projeto abrangente que contemple toda a complexidade de seus múltiplos determinantes e as dinâmicas específicas produtoras da violência em diferentes situações. Concluise que um projeto baseado na solidariedade social, na eqüidade e na democracia só poderá emergir da organização dos grupos sociais atingidos, aliados a militantes em defesa da vida, vindos das mais diversas áreas de atuação e que a epidemiologia tem um importante papel neste processo podendo contribuir para a monitorização da violência, para o conhecimento de realidades especificas e para a sensibilização e instrumentalização dos atores sociais engajados na transformação das condições geradoras da violência.
\end{abstract}

PALAVRAS-CHAVE: epidemiologia da violência, desigualdades sociais, informações de mortalidade, homicídios, segregação urbana.

* Médico Sanitarista do Programa de Aprimoramento das Informações de Mortalidade no Município de São Paulo PRO-AIM - Viaduto Dona Paulina - Baixos. São Paulo - SP CEP: 01501020 - Tel/fax: (11) 237 7038 - e-mail: mdrumond(a) uninet.com.br 


\section{INTRODUÇÃO}

A epidemiologia tem sido um instrumento importante no conhecimento da realidade de saúde e das condições de vida das populações. No entanto, este conhecimento freqüentemente não se traduz em ações visando à mudança dos quadros detectados. A falta de intenção política de enfrentar os problemas é muitas vezes o fator determinante dessa inércia. A violência tem sido um objeto ainda pouco abordado na área da saúde, o que contradiz com a importância que o tema tem aparecido entre as maiores preocupações nas sociedades modernas, em especial nas grandes cidades e em seu entorno. Muitas vezes, mesmo que se pretenda tomar a violência como problema de saúde pública, defronta-se com a complexidade da sua abordagem, uma vez que ao contrário de muitos outros problemas da área, a violência tem raízes em determinações múltiplas e interrelacionadas, que atravessam objetos de diferentes disciplinas e setores da sociedade. A estas dificuldades soma-se a falta de acesso e produção de informações adequadas, o que muitas vezes impede o conhecimento do problema e a orientação de intervenções.

$\mathrm{Na}$ área da saúde, a construção de sistemas de informações epidemiológicas que efetivamente contribuam para a elaboração e condução de políticas sociais é desafio ainda em processo. As inadequações são de diversos tipos. Muitas vezes, as informações produzidas se restringem a uma visão genérica de grandes unidades geográficas, com acesso restrito aos niveis centrais do sistema de saúde. Mesmo neste nivel, é comum que as informações não sejam analisadas, e mesmo quando isto ocorre, utilizam-se indicadores tradicionais e gerais, incapazes de especificar os problemas de maneira a orientar as ações para seu enfrentamento. Os niveis descentralizados do sistema, por sua vez, têm grandes dificuldades de acesso às informações que the permitam conhecer a sua realidade específica, o que é agravado pelo processamento centralizado e disponibilização tardia, impossibilitando o desencadeamento de intervenções imediatas. Outro problema nos niveis descentralizados do sistema é a carência de projetos e metodologias, adequados a estes níveis, para o uso destas informações como instrumento de trabalho cotidiano. Estes fatores têm restringido os níveis descentralizados a meros coletores e repassadores de dados brutos, numa rotina burocrática e desestimulante. Estas dificuldades têm contribuído para a perda do potencial para utilização transformadora da informação epidemiológica. 
As informações de mortalidade estão entre as mais importantes na área da saúde. O óbito é evento único e de registro obrigatório. Seu sistema de informação é universal, de base populacional, de codificação padronizada, permitindo avaliação de tendências, comparações com outros locais e o conhecimento dos padrões de mortalidade de uma sociedade e seus grupos sociais. Além disso, a experiência da área da saúde na localização de eventos tem conseguido aprofundar o conhecimento sobre realidades específicas, o que permite grandes contribuições na abordagem dos problemas. Devese considerar, no entanto, que as informações de mortalidade têm uma grande limitação por tratar-se de um evento fatal, final. No entanto, o acesso imediato às informações de mortalidade pode permitir o desencadeamento de ações de vigilância da morte evitável através da investigação dos casos, o que pode informar sobre fatos que ocorreram no percurso que levou à morte ou sobre as condições de vida das localidades ou dos grupos populacionais avaliados, podendo, desta forma, ser utilizado como evento sentinela da qualidade das ações executadas pelos serviços de saúde (RUTSTEIN, et al., 1976) e das condições de vida da população.

\section{O PRO-AIM - Programa de Aprimoramento das Informações de Mortalidade no Município de São Paulo}

O Programa de Aprimoramento das Informações de Mortalidade no Município de São Paulo (PRO-AIM) foi criado em 1989. Tratou-se de uma iniciativa desencadeada no processo de construção do Sistema Único de Saúde (SUS), no desafio da produção de informações epidemiológicas para dar base à atuação das equipes de saúde nos diversos niveis do sistema. O PRO-AIM foi estruturado com base no acesso rápido, na melhoria da qualidade e na descentralização da informação produzida. Porém mais importante foi o novo enfoque desenvolvido, ao tomar o óbito como um caso epidemiológico, mas buscando ampliar a visão para além do caso, ou seja, para as condições geradoras dos problemas que captava. A criação do PRO-AIM permitiu a transformação do sistema de informações de mortalidade na cidade de São Paulo, de um sistema passivo e distante dos problemas de saúde no tempo e no espaço, para uma abordagem focada na especificação de problemas, no desencadeamento da vigilância da morte evitável, na promoção de iniciativas de melhoria da qualidade das informações produzidas, além da monitorização da mortalidade na cidade de São Paulo através do seu acompanhamento permanente e atualizado. 
A atividade do PRO-AIM é desencadeada através do acesso rápido às declarações de óbitos ocorridos no município de São Paulo. Todas as manhãs, chegam até o programa cerca de $\mathbf{2 0 0}$ declarações dos óbitos ocorridos, no dia anterior, na cidade. Desta forma, pode-se notificar e desencadear ações de vigilância relativas a diversos sistemas e projetos em andamento tais como o tradicional sistema de vigilância epidemiológica das doenças de notificação compulsória, do qual o PRO-AIM é fonte complementar ou as investigações do Comitê para o Estudo e Prevenção da Morbimortalidade Materna da Prefeitura de São Paulo ou das mortes de crianças matriculadas em creches e centros da juventude da Secretaria de Bem Estar Social, também da Prefeitura. Outra atividade viabilizada pelo acesso rápido é o contato com os médicos declarantes e serviços, em casos em que as declarações foram preenchidas de forma incorreta, imprecisa ou mesmo quando sugerem a existência de agravos não registrados, tal como a Aids (DRUMOND et al., 1996/97). Através desta atividade, o PRO-AIM busca esclarecimento sobre cerca de 3000 óbitos por ano na cidade de São Paulo, o que equivale a $5 \%$ do total ocorrido na cidade, entre residentes. $O$ acompanhamento permanente da mortalidade viabiliza, ainda, a monitorização de situações e intervenções com reflexos na assistência e nas condições e qualidade da vida na cidade, tal como ocorre com o acompanhamento de agravos, como os relacionados ao trânsito e à poluição atmosférica e na avaliação da implementação de políticas de saúde, como no caso da disponibilização da terapia anti-retroviral combinada para Aids, entre outras.

\section{A QUALIDADE DA INFORMAÇÃO SOBRE VIOLÊNCIA NA CIDADE DE SÃO PAULO}

Com relação à qualidade das informações sobre violência, o PRO-AIM incorporou na sua rotina, desde 1996, a busca de informações adicionais, junto ao Instituto Médico Legal (IML-Central), em todos os casos de mortes por causas externas atestadas como acidentes sem a especificação da causa e como lesões de intenção indeterminada. Nesta atividade, o PRO-AIM tem esclarecido grande parte dos casos investigados, o que permite aprimorar a qualidade da sua informação e ampliar a sua utilização. Estudo realizado pelo PRO-AIM (DRUMOND et al., 1999) mostrou a importância destas buscas adicionais na melhoria da qualidade dos dados sobre mortalidade por causas externas, pois observou-se que o IML não utiliza as informações disponiveis na própria instituição para o preenchimento das declarações de óbito. Por outro lado, constatou-se que, ao contrário de outros locais no Brasil, as informação sobre os homicídios na cidade de São Paulo são de boa qualidade, no que diz respeito à especificação do tipo de violênicia, o 
mesmo não podendo ser afirmado sobre a especificação dos meios utilizados para produzir a violência.

Porém, se estas atividades têm sido importantes para a melhoria da qualidade das informações sobre violência na cidade de São Paulo permitindo uma ampliação dos seus usuários, modificações recentes na declaração de óbito trazem novas dificuldades na utilização das informações sobre causas externas em todo o país. Sob a alegação de que o campo 46 da DO (se acidente, especificar o tipo) não era preenchido, este foi retirado da declaração e substituido pelo espaço para a descrição sumária do evento. Estimativas iniciais indicam que haverá um aumento de cerca de $120 \%$ nos acidentes e eventos indeterminados na cidade de São Paulo em função desta modificação, que foi implementada sem uma avaliação da sua pertinência ou maiores discussões com representações municipais. $O$ argumento de que o campo 46 não era preenchido pode ser avaliado pela consulta às bases de dados do Ministério da Saúde (MINISTÉRIO DA SAÚDE, 1998) onde se constata que entre 1993 (quando não existia o campo na DO) e 1996 (quando este já estava implementado em todo o Brasil) aumentou em $20 \%$ o número de acidentes especificados nas estatísticas de mortalidade nacionais, sendo que os atropelamentos tiveram um aumento de quase $100 \%$. Outra constatação, analisando as bases de dados do ano de 1996, é que este campo era preenchido em $65,1 \%$ dos casos pertinentes e especificava as causas dos acidentes em $58,2 \%$ das mortes atestadas como acidentais (campo 45), no Brasil, sendo que no Estado de São Paulo este percentual era de $85,3 \%$. Não têm sido raras as modificações na declaração de óbito a cada edição, o que tem dificultado a utilização dos dados do Sistema de Informações de Mortalidade (SIM) pela impossibilidade da análise de séries históricas sobre alguns agravos e variáveis da declaração de óbito.

\section{OS HOMICÍDIOS NA CIDADE DE SÃO PAULO}

O potencial do uso das informações de mortalidade como geradoras de conhecimento específico da realidade sanitária e a importância da monitorização da violência foi analisado neste artigo através das informações sobre a principal causa externa de mortalidade na cidade de São Paulo, no Estado de São Paulo e no Brasil, que são os homicídios. Não pretende-se discutir de forma aprofundada os determinantes dos homicídios na cidade de São Paulo. Seria necessário muito mais espaço e competência, mas além disso, é tamanha a complexidade desta discussão, que setores isolados teriam muitas dificuldades para fazê-lo, tamanha é a diversidade e complexidade 
dos determinantes das agressões. O que se constata é que a saúde pública, com tantas histórias de sucesso no controle de alguns agravos que atingem as populações, como a variola e a poliomielite, tem acumulado fracassos sucessivos nos seus objetos mais complexos. Se isto ocorre em casos em que as tecnologias voltadas à prevenção e controle são conhecidas, como cólera e dengue, torna-se ainda mais grave ao abordar um objeto tal como os homicídios, problema sobre o qual não existe, ao menos, um consenso sobre o que fazer, o que sugere não haver, para a área da saúde pública, objeto de abordagem mais complexa.

A falta de um modelo explicativo abrangente sobre os homicídios tem gerado propostas de intervenções, quase sempre, parciais e que refletem a visão setorial do seu formulador. Qualquer tentativa de apresentação de um modelo explicativo neste espaço seria generalista e simplista. Por esta razão, serão apenas citados alguns dos determinantes que têm sido levantados como exemplos das dificuldades da sua abordagem. As condições econômicas geradoras das desigualdades sociais, do desemprego e da miséria têm relação íntima com a violência, assim como as condições sociais de vida cotidiana da população e a ausência de políticas públicas. Considera-se ainda o crescimento da posse de armas de fogo, o consumo de drogas ilegais ou não, como o álcool, a falta de opções de lazer e o crescimento absoluto e relativo das populações jovens, assim como o tráfico de drogas com as disputas por pontos de venda, as cobranças de dividas e organizações como o esquadrão da morte ou os matadores de aluguel. A ausência e morosidade da justiça, o esgotamento e baixa eficácia do sistema prisional, a pouca utilização de penas alternativas, o policiamento ineficaz, sucateado, desvalorizado e corrupto, além de aspectos éticos como a valorização do individualismo e a banalização da vida, e os comportamentos agressivos e cruéis. Estes determinantes, entre outros, se relacionam de formas diferenciadas em situações diversas, de maneira que, mesmo que um modelo abarcasse toda esta complexidade, ele não poderia ser generalizado

A escolha de uma metodologia para analisar um fenômeno de tal complexidade não é tarefa fácil. Optou-se por utilizar os instrumentais da epidemiologia descritiva considerada potente o suficiente para orientar politicas públicas e contribuir na transformação das condições geradoras da violência. Desta forma, utilizou-se informações da base de dados do PRO-AIM, entre os anos de 1991 e 1999. Os dados foram distrivuídos e analisados segundo características das pessoas, tempo e espaço. As declarações de óbitos do PRO-AIM se referem aos residentes no Município de São Paulo e que ocorreram 
também no município. Foram valorizados os números absolutos e suas distribuições de freqüência, além dos coeficientes de mortalidade e as razões entre coeficientes de áreas diversas da cidade. Foram exploradas as variáveis da declaração de óbito que pudessem contribuir para uma especificação do conhecimento sobre o fenômeno analisado. Buscase aprofundar este conhecimento pela análise dos diferenciais no espaço urbano. Devese esclarecer que o espaço urbano não será considerado pela dinâmica específica da sua produção e sim como uma variável contextual social, utilizando-se a divisão da cidade de São Paulo em 96 distritos administrativos e no agrupamento de distritos e subdistritos de paz em áreas socioambientais homogêneas (STEPHENS et al., 1994). Entende-se que considerar os diferentes espaços homogêneos pode constituir uma estratégia para o entendimento da ocorrência e distribuição de agravos à saúde de diferentes grupos sociais da população que habitam esses espaços. Além disso, como os serviços públicos, assim como muitos movimentos populares são organizados em base local, estes conhecimentos podem contribuir para a discussão e a adequação das ações sociais às necessidades diferenciadas da população.

\section{RESULTADOS E DISCUSSÃO}

Distribuindo-se as mortes, na cidade de São Paulo, do ano de 1998 segundo a lista brasileira de mortalidade, observa-se que os homicídios se encontram na $3^{\text {a }}$ posição, representando $8,4 \%$ do total de mortes e sendo superados apenas pelas doenças isquêmicas do coração e pelos acidentes vasculares cerebrais. Esta situação difere segundo gênero pois enquanto os homicídios aparecem como a $12^{\mathrm{a}}$ causa de morte entre as mulheres, são a primeira no sexo masculino em 1998. Com relação a faixa etária, observa-se que os homicídios foram a principal causa de morte entre 10 e 39 anos, na cidade, sendo que este período etário se amplia entre os homens até os 49 anos. Porém, mesmo entre as mulheres, os homicídios aparecem como a principal causa de morte na cidade, de 15 a 29 anos.

A evolução temporal pode ser observada pelo gráfico 1 que mostra o número de homicídios segundo o semestre entre 1991 e 1999. Observa-se a tendência de crescimento atingindo o maior valor no $1^{\circ}$ semestre de 1999 . O coeficiente de mortalidade por homicídios em 1998, entre residentes e ocorridos na cidade, foi de 53 por 100.000 habitantes. No gráfico 2 estão apresentados os números mensais entre janeiro de 1991 e junho de 1999. Observa-se que com a exceção do ponto isolado em fevereiro de 1991, é a partir do final de 1994 que os homicídios passam a superar os valores de 400 ao mês 
sendo que este fato torna-se mais consistente a partir do final do ano de 1998, mantendose em 1999, quando um novo patamar parece consolidado, inclusive com a manutenção destes altos índices mesmo nos meses de inverno, quando estes valores freqüentemente apresentavam quedas.

Observa-se que, pela importância no conjunto das causas de morte, crescimento e dimensão, os homicidios são um grave problema social na cidade de São Paulo. Em especial comparando-se com duas causas de morte de importância na cidade, em anos recentes, como a aids e os acidentes de trânsito, que vêm apresentando queda desde 1997. Entre 1996 e 1998, enquanto a aids e os acidentes de trânsito apresentaram uma redução de mortes de $44 \%$ e $34 \%$, os homicídios cresceram mais de $8 \%$ no mesmo periodo. No entanto, o perfil dos homicídios na cidade de São Paulo começa a ficar mais definido analisando os dados de diferentes grupos sociais, utilizando as variáveis disponiveis na declaração de óbito.

Considerando o grau de instrução entre pessoas de 10 anos ou mais, estudo do PRO-AIM sobre o ano de 1997 (PREFEITURA DO MUNICIPIO DE SÃO PAULO, 1999) mostrou que os homicídios são a $2^{\mathrm{a}}$ causa de morte entre pessoas com instrução ignorada e até o primeiro grau, ficando na décima terceira posição entre pessoas de nível superior. Com relação à ocupação, estudo sobre 1995 (PREFEITURA DO MUNICÍPIO DE SÃO PAULO, 1997) mostrou que entre os homens, os homicídios são a principal causa de morte, entre 15 e 64 anos, nos grupos de trabalhadores do comércio, de serviços pessoais, da indústria de transformação e condutores de veículos e de braçais. Entre as mulheres, na mesma faixa etária, os homicídios dividiram com a Aids a primeira posição entre trabalhadoras em serviços pessoais. Análise preliminar da base de dados entre junho de 1998 e julho de 1999 mostra que o perfil de mortalidade segundo a cor na cidade de São Paulo apresenta os homicidios como principal causa de morte entre pessoas de cor parda e preta.

Com base nas informações apresentadas, pode-se traçar um perfil da vítima predominante dos homicídios em São Paulo como homens, adultos jovens, de baixa instrução, com ocupação nos setores industrial e de serviços ou de baixa qualificação, e de cor preta e parda, permitindo uma primeira aproximação sobre as desigualdades sociais na distribuição dos homicídios na cidade de São Paulo. No entanto, os dados segundo região de residência, com denominadores disponiveis, permitem analisar " 'Tuns outros aspectos importantes dos homicídios na cidade. A tabela 1 mostra os dez distritos 
com os maiores coeficientes de mortalidade da cidade, no ano, o distrito com o menor coeficiente e os valores do coeficiente da cidade, o maior e o menor, assim como a razão entre os coeficientes extremos em 1995, 1996, 1997 e 1998. Observa-se uma repetição dos distritos com taxas elevadas. Os moradores do Jardim Ângela, do Capão Redondo, do Jardim São Luís e de Guaianazes estão sempre expostos aos maiores riscos. O oposto ocorre com os moradores da Consolação, de Perdizes e do Jardim Paulista, entre outros, sempre entre os menores. Outro aspecto importante são os distritos emergentes como a Brasilândia e o Iguatemi que aparecem entre os primeiros, em anos mais recentes. Com relação à Brasilândia pode-se destacar o coeficiente de mortalidade por homicídios entre homens adultos jovens de 15 a 24 anos, em 1998, que foi de 494 por 100.000 (dado não apresentado na tabela). Isto significa que, em 1998, para cada grupo de 200 homens entre 15 e 24 anos residentes na Brasilândia, um foi assassinado!

Um outro aspecto que pode ser ressaltado da tabela são os diferenciais relativos, ou a razão entre os coeficientes analisados. Observa-se, comparando os extremos dos anos apresentados, que o menor risco relativo foi de 15 , o que significa que o risco de morrer assassinado por residir em distritos com altos coeficientes foi 15 vezes maior do que de ser assassinado por residir em algumas áreas nobres. Destaca-se o no ano de 1997, que apresentou uma razão de 58,5 vezes, entre o risco de morrer assassinado por residir na Brasilândia, numa comparação com no distrito da Consolação.

A gravidade das desigualdades sociais na distribuição dos homicídios na cidade pode ser confirmada analisando-se as tendências segundo grupos sociais residentes em diferentes áreas sócio-ambientais homogêneas. O gráfico 3 mostra que o crescimento dos homicidios ocorre nas áreas de residência da população em piores condições socioambientais (AH 4). Interessante ressaltar que estes dados não dão sustentação para a discussão atual dominante sobre os homicídios na cidade de São Paulo. $O$ problema é tratado como se esta violência atingisse da mesma maneira todos os grupos sociais. Mapa da violência da cidade de São Paulo (CEDEC, 1996) mostra que enquanto nas áreas de residência da população em piores condições predomina o crime contra a vida, nas áreas nobres o que predomina é o crime contra o patrimônio.

No entanto, é preciso alguns cuidados para não estabelecer uma relação mecânica entre homicídios e periferia da cidade, tomada genericamente. Observou-se na tabela 1 que as regiões degradadas do centro velho da cidade como a Sé e o Brás estão também entre as áreas de maior risco de homicídio da cidade. Outro exemplo que 
pode desfazer equívocos se refere ao Morumbi, no ano de 1996. Este distrito, considerado um símbolo da pujança da capital paulista, apresentou-se, naquele ano, na sétima posição como um dos distritos mais violentos da cidade. No Mapa da Exclusão/Inclusão Social da Cidade de São Paulo (SPOSATI, 1996), que analisou os 96 distritos da cidade segundo indicadores de autonomia, qualidade de vida, desenvolvimento humano e eqüidade, 0 Morumbi foi classificado na décima segunda posição entre os distritos, estando na faixa da inclusão social. Dados divulgados pela pesquisa mostravam seu destaque, na cidade, no maior número de cômodos e banheiros por domicílio (característica de suas mansões) e na maior concentração de rendimentos imobiliários ou taxa de lançamento de prédios residenciais, entre todos os distritos da cidade. Naquele ano ocorreram 27 assassinatos no Morumbi. Localizando espacialmente estes homicídios observa-se que 9 deles foram na favela do Real Parque, 10, incluindo uma chacina com 7 mortos, foi na favela do Jardim Panorama e 4 foram na favela do Porto Seguro totalizando 23 homicídios de moradores de favelas da região.

Tomando o número médio de moradores por domicílio e o número de unidades habitacionais nestas 3 favelas, segundo dados da Secretaria da Habitação do Município de São Paulo, chega-se a um coeficiente aproximado de mortalidade por homicídios de 335 por 100.000 habitantes, número só comparável à localidades em situação de guerra! No entanto, o mais surpreendente é constatar que não se comentou que naquele ano o Morumbi havia se apresentado como um local violento da cidade de São Paulo, ou seja, os coeficientes altíssimos observados foram tomados como rotineiros. Em tempo, utilizando outra variável da declaração de óbito, observou-se que a ocupação das outras 4 pessoas assassinadas cujos endereços de residência não se localizavam nas favelas eram vigilante, lavadeira, pintor de automóveis e motorista. Este quadro grave das desigualdades sociais na especificação da violência no Morumbi é apenas um exemplo que permite demonstrar as condições de violência cotidianas da cidade de São Paulo. Análises semelhantes já foram exploradas pelo PRO-AIM com respeito a outros distritos heterogêneos da capital paulista como na Vila Andrade (Favela do Paraisópolis) ou na Vila Leopoldina (favela do CEAGESP), com resultados semelhantes.

É importante ressaltar que existem diversas pautas de investigações epidemiológicas em aberto com respeito aos homicídios na cidade de São Paulo. Uma, diz respeito à especificidade da violência em regiões de altos índices e aparentemente homogêneas. Já se observou, pelos dados do PRO-AIM, que a violência na Brasilandia 
se concentra na região próxima ao Jardim Vista Alegre, enquanto no Jardim Ângela os homicídios são mais espalhados. Outra pauta não explorada parte da observação de que numa mesma região, o espaço onde predomina a violência nem sempre é o mesmo onde predomina a mortalidade infantil e outros agravos relacionados às piores condições de vida, sugerindo determinações muitas vezes diversas. Estes são alguns exemplos de especificações que necessitam aprofundamentos posteriores em novos estudos e que podem ser desenvolvidos a partir da base de dados disponivel do PRO-AIM.

Observa-se, pelos dados apresentados, que os homicídios na cidade de São Paulo apresentam altos níveis, são crescentes e apresentam uma distribuição desigual, sempre atingindo populações nas piores situações socioeconômicas, qualquer que seja a variável social explorada da declaração de óbito. Estes dados sugerem, ainda, a existência de diferentes dinâmicas locais na produção social da violência na cidade e a necessidade de abordagens diferenciadas das situações geradoras da violência para cada um destes espaços. A análise e acompanhamento das informações sobre homicídios poderiam aprimorar as intervenções visando sua redução e tornar-se parâmetros para avaliação de metas. Este quadro revela, também, o fracasso na prevenção e combate aos homicídios pelas medidas habituais. Estas têm sido setorizadas, sendo a mais comum o deslocamento e reforço de policiamento ostensivo. Parece claro que as dinâmicas produtoras da violência na cidade são generalizadas e qualquer deslocamento de policiamento, se eficaz em reduzir os níveis em uma região específica, deslocam também os crimes para regiões diversas.

Entre as possiveis intervenções, um exemplo sempre citado de prevenção e combate a violência tem sido as medidas adotadas pela Prefeitura de Nova York voltadas à tolerância mínima a crimes leves. Estas medidas parecem ter sido eficazes para a cidade de Nova York que apresentou coeficiente de mortalidade por homicídios de 13,3 por 100.000 habitantes em 1996. O problema é tomar uma medida isolada em Nova York como se fosse o projeto global. Em Nova York outros aspectos geradores da violência já vêm sendo abordados há mais tempo, tais como o combate ao tráfico de drogas ou as políticas sociais voltadas às populações de maior risco. Além disso, o contexto econômico de desemprego e concentração de renda não se apresentam, da mesma forma que em São Paulo, naquela cidade. Ou seja, não parece pertinente uma comparação da situação de Nova York com a situação de São Paulo, tomando apenas uma medida isolada e deixando de lado todos os outros determinantes geradores da violência. 
Experiência mais próxima da nossa realidade ocorreu em Cali na Colômbia quando o médico sanitarista Rodrigo Guerrero assumiu a prefeitura da cidade, eleito por uma coligação de partidos de esquerda, implantou um programa de prevenção e combate à violência denominado DESEPAZ (Desenvolvimento, Segurança e Paz). As medidas tomadas eram voltadas para uma abordagem ampla dos determinantes dos homicídios, entre outras violências, englobando ações voltadas à promoção da eqüidade e desenvolvimento social, educação para a paz, fortalecimento institucional e estudo permanente sobre a violência, com contribuições da epidemiologia. Entre as medidas destaca-se o estímulo à criação de micro-empresas comunitárias, implementação de olimpiadas inter-comunais estimulando os jovens a uma competição sadia, agilização da justiça, adequação delito e punição, reforma e reaparelhamento da polícia, desarmamento voluntário, incluindo o "desarmamento" simbólico de brinquedos infantis, proibição do porte de armas entre 18 horas de sexta e 6 horas de segunda-feira, proibição da venda e consumo de bebidas alcóolicas após meia-noite e criação de personagem na mídia que caracterizava o jovem estimulador da violência - "el bibo bobo" (GUERRERO, 1996). Entre as medidas, incluiu-se a produção e divulgação sistemática de informações sobre a violência através de informes epidemiológicos semanais, que permitiam um aprofundamento do conhecimento sobre a violência naquela cidade e orientavam a implementação de novas medidas. As intervenções conseguiram baixar o coeficiente de homicídios em $15 \%$ no primeiro ano de sua aplicação, o que representou uma grande conquista, dados os altíssimos índices de violência naquela cidade e país. Esta experiência tem inspirado a implementação de uma vigilância epidemiológica da violência (CONCHA, et al., 1996).

A característica mais importante desta proposta é a implementação de um projeto global de prevenção e controle da violência que atravessa todos os setores da sociedade abordando seus mais diversos determinantes. Tomando-se as políticas sociais brasileiras recentes de distribuição gratuita da terapia anti-retroviral combinada para a Aids e o Código Nacional do Trânsito, pode-se constatar os benefícios de projetos globais na redução da mortalidade por alguns dos maiores problemas nacionais. Porém a implantação e manutenção destes projetos exige o engajamento da sociedade. O recente abrandamento da pontuação de infrações do Código Nacional do Trânsito e a ameaça de descontinuidade do tratamento da Aids por falta de verba federal são apenas alguns exemplos das dificuldades no processo de manutenção de políticas sociais no Drasil, mesmo quando apresentam resultados positivos. Os grupos contrários à implementação dos projetos, seja porque se beneficiam ou lucram com os problemas, seja porque 
competem pela distribuição dos orçamentos institucionais, também se organizam e pressionam. Na ausência de definições claras de prioridades por parte do Estado, cabe à sociedade civil organizada as iniciativas para manter e implementar as políticas sociais necessárias.

\section{CONCLUSÕES}

A realidade dos homicidios na cidade de São Paulo ainda não foi suficiente para gerar a discussão de um projeto abrangente contra a violência, nem a indignação da sociedade como um todo. A necessidade de um consenso social vai contra as iniciativas que têm sido desenvolvidas. A distribuição dos homicídios é tão desigual, que a violência localizada nos grupos sociais vivendo em piores condições socioambientais, de alguma forma, parece aliviar as populações de alta renda e maior poder de pressão, que se contentam em buscar soluções individuais ou mesmo coletivas de reforço do policiamento privado, alarmes, guaritas, travas de segurança, apólices de seguro, elevação dos muros, criação de condomínios fechados ou iniciativas de defesa pessoal. O que predomina, como demanda destes grupos sociais, é a proteção dos ricos contra os pobres. $O$ movimento Viva São Paulo, gerado pela indignação de parcela da sociedade em decorrência do crime no Bar Bodega, é exemplo de uma proposta que reforça o aumento da segregação social.

O Estado, em todos os níveis, restringindo quase sempre sua parcial atuação à área da segurança pública, vai trocando de comando em resposta aos fracassos sucessivos. Enquanto isto, a violência cresce, a cada semana morrem assassinadas mais de 100 pessoas em São Paulo, são cerca de 15 homicídios por dia, 12 deles na periferia, praticamente todos nos grupos vivendo em piores condições sociais. Neste contexto, a população de São Paulo assiste amedrontada a elevação de seus homicídios como um programa de televisão. A violência gera muito lucro e a sociedade, alicerçada em valores como competição, liberdades privadas individuais e desigualdades naturais vai banalizando e relevando este grave problema. Neste contexto, a cidadania inexiste, os cidadãos são supérfluos, irrelevantes, sendo que a perda do direito à vida se torna a última etapa de um percurso de privações.

Um projeto abrangente de prevenção e controle dos homicídios na cidade de São Paulo, nos moldes da experiência de Cali-Colômbia, parece que vai ter que partir da parcela da sociedade afetada cotidianamente pelo problema, como algumas experiências 
localizadas têm demonstrado. Apenas um projeto nascido no movimento popular organizado, de valorização da solidariedade, da eqüidade e da democracia pode ser um ponto de partida para a transformação ampla das condições produtoras da violência na cidade e criação de um consenso social ciente da necessidade de ação. Um movimento com estas características seria respaldado pelo engajamento de parlamentares, técnicos, pesquisadores, juristas, enfim de militantes em defesa da vida dos mais diversos campos de atuação, sensibilizados para a luta pelo fim da violência.

Neste projeto existe um papel para a epidemiologia. Esta pode participar com contribuições teóricas e metodológicas, analisando, produzindo e fornecendo informações que instrumentalizem os atores sociais envolvidos no projeto e denunciando esta barbárie em que tem se transformado a vida social brasileira, em especial nas grandes cidades. O PRO-AIM, neste contexto e no seu âmbito, permanece produzindo e monitorizando informações cotidianas, aprofundando análises, buscando a melhoria da qualidade das informações, disponibilizando os dados para toda a sociedade interessada e divulgando informações que possam contribuir para a denúncia e transformação do quadro atual.

\section{REFERÊNCIAS BIBLIOGRÁFICAS}

CEDEC (Centro de Estudo de Cultura Contemporânea). Mapa de risco da violência: cidade de São Paulo. São Paulo, CEDEC, 1996.

CONCHA, A.; GUERRERO, R.; PHEBO, L.; MIGLIÔNICO, A. Vigilância epidemiológica de homicídios y suicidios; Informe del Taller de Cali. Bol. Ofic. Sanit. Panamer., 120 (4):316-24, 1996.

DRUMOND, JR., M.; LIRA, M.M.T.A.; FREITAS, M. NITRINI, T.M.V. A Aids e os sistemas de informações de mortalidade em nível local: a experiência do PRO-AIM no Município de São Paulo. AIDS - Bol. Epidemiol. 9 (5):3-8, 96-7.

DRUMOND, JR., M.; LIRA, M.M.T.A., FREITAS, M., NITRINI, T.M.V.; SHIBAO, K. Avaliação da qualidade das informações de mortalidade por acidentes não especificados e eventos com intenção indeterminada. Rev. Saúde Pública, 33(3): 273-80, 1999.

GUERRERO, R. Exposição da experiência de abordagem dos homicídios em CaliColômbia em grupo de trabalho para implantação da vigilância epidemiológica da violência no Estado de São Paulo coordenado pela Secretaria Estadual de Saúde de São Paulo, setembro de 1996. 
MINISTÉRIO DA SAÚDE Sistema de Informaçס̃es de Mortalidade, 1979-1996; dados de declaração de óbito. Brasília, 1998. [CD-ROM]

PREFEITURA DO MUNICÍPIO DE SÃO PAULO Mortalidade e grau de instrução na cidade de São Paulo. Bol. PRO-AIM, (33), 1999.

PREFEITURA DO MUNICÍPIO DE SÃO PAULO Ocupação e mortalidade no Município

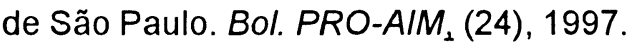

RUTSTEIN, D.D.; BERENBERGER, W.; CHALMERS, T.C.; FISHMEN, A. P.; PERRIN, E.B. Measuring the quality of medical care. N. Engl. J. Med, 294:582-88, 1976.

SPOSATI, A. coord. Mapa da exclusão/inclusão social da Cidade de São Paulo. São Paulo, EDUC, 1996.

STEPHENS, C.; TIMAEUS, I.; ACKERMAN, M.; AVLE, S.; MAIA, P.B.; CAMPANÁRIO, P.; DOE, B.; LUSH, L.; TETTE, H.; HARPHAM, T. Environment and health in developing countries: an analysis of intra-urban differentials using existing data. São Paulo, London School of Hygiene \& Tropical Medicine. Fundação SEADE, 1994.

SUMMARY: This article aims at describing and discussing the epidemiology of homicide in São Paulo City with emphasis on its social inequalities. The study used data and the experience of the Program for the Improvement on Mortality Information of São Paulo City (PRO-AIM). The empirical results show that the importance, dimension and trend of the homicides are on the increase in São Paulo City, and bring to light the large social inequalities in all the analyzed aspects based on death certificate variables. The intra-urban space distribution reveals that indicators are high in the periphery and old derelict downtown areas. The differentials were also analyzed in a district with good social conditions. Homicide prevention and control proposals are discussed and emphasis is placed on a broad range project that takes into account the complexity of multiple determinants and the specific dynamics that produce violence in different areas. The article concludes that a project based on social solidarity, equity and democracy can only emerge from the organization of the affected social groups in partnership with militants for the defense of life coming from all fields of action. Epidemiology plays an important role in this process contributing to the monitoring of violence, production of specific knowledge and supplying information to social actors engaged in changing the conditions that produce violence.

KEY WORDS: violence epidemiology, social inequalities, mortality, homicides, urban segregation. 
TABELA 1: Classificação dos 10 distritos administrativos da Cidade de São Paulo com os maiores coeficientes de mortalidade por homicídios, coeficiente de mortalidade por homicídios por 100.000 habitantes da cidade, do distrito com maior valor, do distrito com menor valor e razão entre os coeficientes do maior e do menor valor nos anos de 1995, 1996, 1997 e 1998.

\begin{tabular}{|c|c|c|c|c|}
\hline & \multicolumn{4}{|c|}{$\mathrm{ANO}$} \\
\hline CLASSIFICAÇÃO & 1995 & 1996 & 1997 & 1998 \\
\hline $\begin{array}{l}10 \\
20 \\
30 \\
40 \\
50 \\
60 \\
70 \\
80 \\
90 \\
100\end{array}$ & $\begin{array}{l}\text { Sé } \\
\text { Jardim Ângela } \\
\text { Brás } \\
\text { Capão Redondo } \\
\text { Grajaú } \\
\text { Jardim São Luiz } \\
\text { Lajeado } \\
\text { Parelheiros } \\
\text { Guaianazes } \\
\text { Vila Curuçá }\end{array}$ & $\begin{array}{l}\text { Jardim Angela } \\
\text { Capão Redondo } \\
\text { Brasilândia } \\
\text { Guaianazes } \\
\text { Jardim São Luiz } \\
\text { Campo Limpo } \\
\text { Morumbi } \\
\text { Cachoeirinha } \\
\text { Cidade Dutra } \\
\text { Parelheiros }\end{array}$ & $\begin{array}{l}\text { Brasilândia } \\
\text { Jardim Ângela } \\
\text { Guaianazes } \\
\text { Capão Redondo } \\
\text { Cidade Dutra } \\
\text { Jardim São Luiz } \\
\text { Grajaú } \\
\text { Cidade Ademar } \\
\text { Vila Andrade } \\
\text { Vila Curuçá }\end{array}$ & $\begin{array}{l}\text { Guaianazes } \\
\text { Jardim Ângela } \\
\text { Brasilândia } \\
\text { Parelheiros } \\
\text { Jardim São Luiz } \\
\text { Iguatemi } \\
\text { Grajaú } \\
\text { Brás } \\
\text { Capão Redondo } \\
\text { Cidade Dutra }\end{array}$ \\
\hline $\begin{array}{l}\text { Coeficiente } \\
\text { Municipal }\end{array}$ & 50,9 & 49,4 & 48,8 & 53,0 \\
\hline $\begin{array}{l}\text { Maior } \\
\text { Coeficiente }\end{array}$ & 98,4 & 85,4 & 101,2 & 88,6 \\
\hline $\begin{array}{l}\text { Distrito e } \\
\text { menor } \\
\text { coeficiente }\end{array}$ & $\begin{array}{c}\text { Perdizes } \\
2,9\end{array}$ & $\begin{array}{c}\text { Jardim Paulista } \\
5,6\end{array}$ & $\begin{array}{c}\text { Consolação* } \\
1,7\end{array}$ & $\begin{array}{c}\text { Jardim Paulista } \\
2,3\end{array}$ \\
\hline $\begin{array}{l}\text { Razão } \\
\text { maior/menor }\end{array}$ & 34,4 & 15,3 & 58,5 & 38,4 \\
\hline
\end{tabular}

FONTE: PRO-AIM - Programa de Aprimoramento das Informações de Mortalidade no Município de São Paulo

* Excluído o distrito de Marsilac onde não houve homicídio em 1997.

OBS: Incluídos os óbitos de residentes na cidade e que ocorreram na cidade. 
Gráfico 1: Número semestral e tenđncia de homicídios entre residentes e ocorridos na Cidade de São Paulo, entre 1991 e 1999

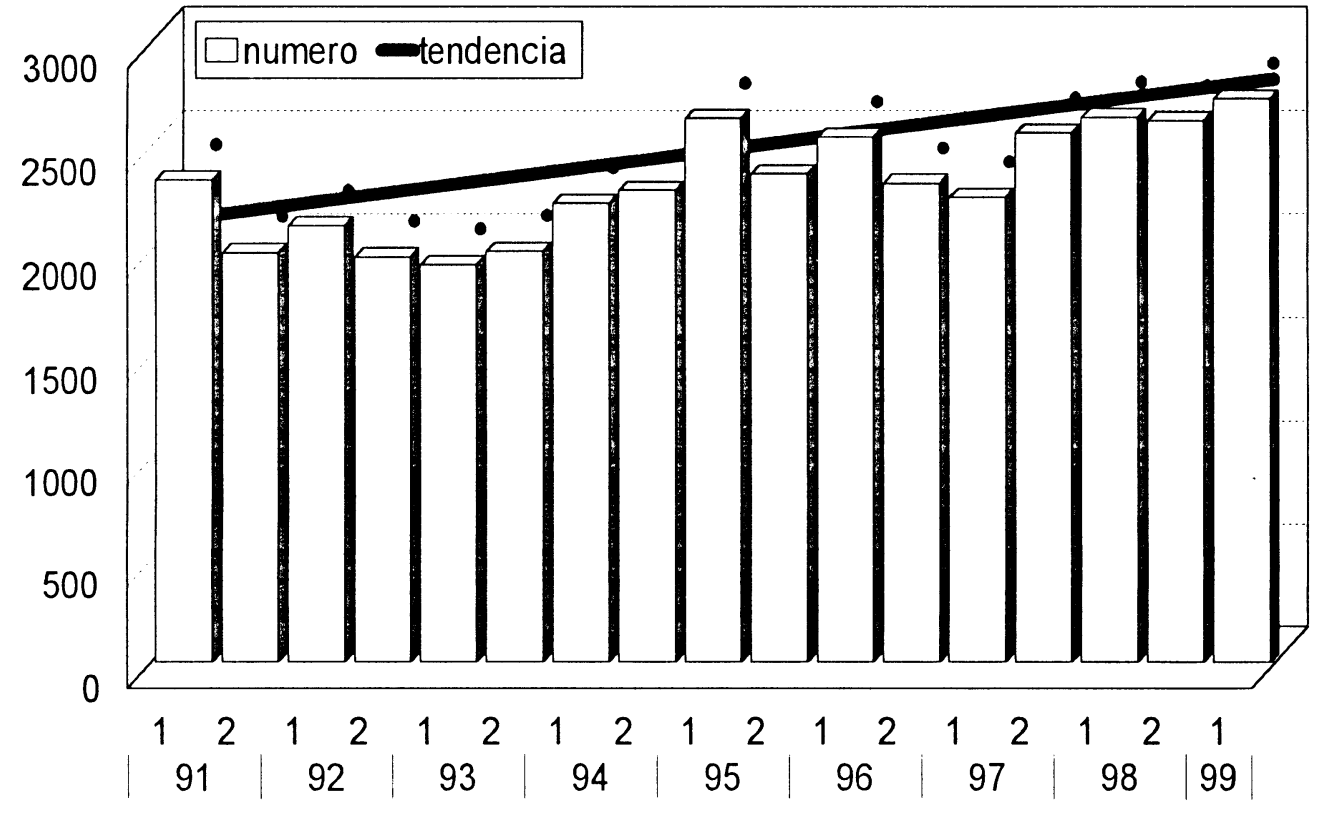

Fonte: PRO-AIM 
Gráfico 2: Número mensal e tenencia de homicídios entre residentes e ocorridos na Cidade de São Paulo, entre janeiro de 1991 e junho de 1999

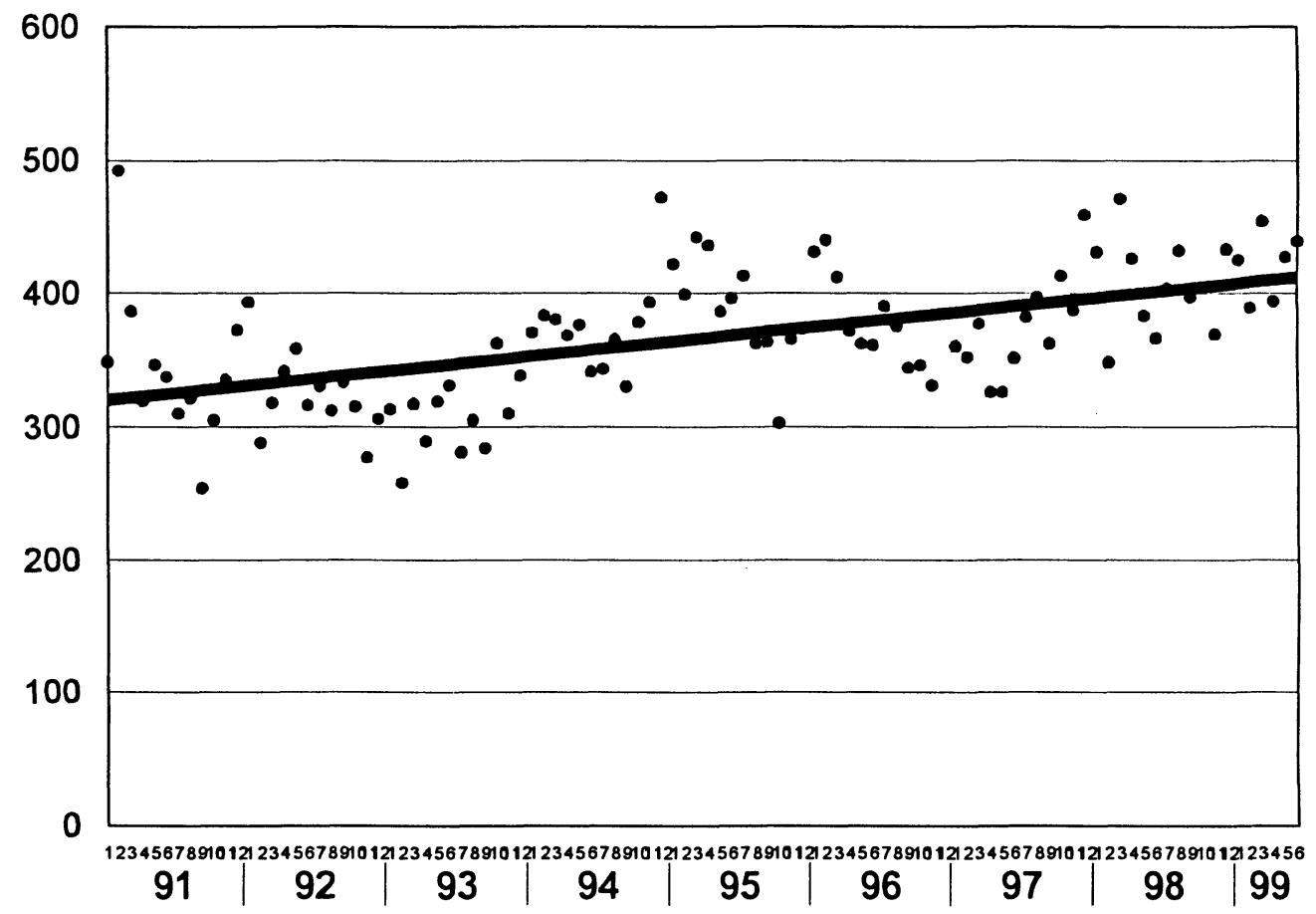

Fonte: PRO-AIM 
Gráfico 3: Número mensal e tenancia de homicídios entre residentes e ocorridos na Cidade de São Paulo segundo áreas sócio-ambientais homoĝneas, entre janeiro de 1991 e junho de 1999

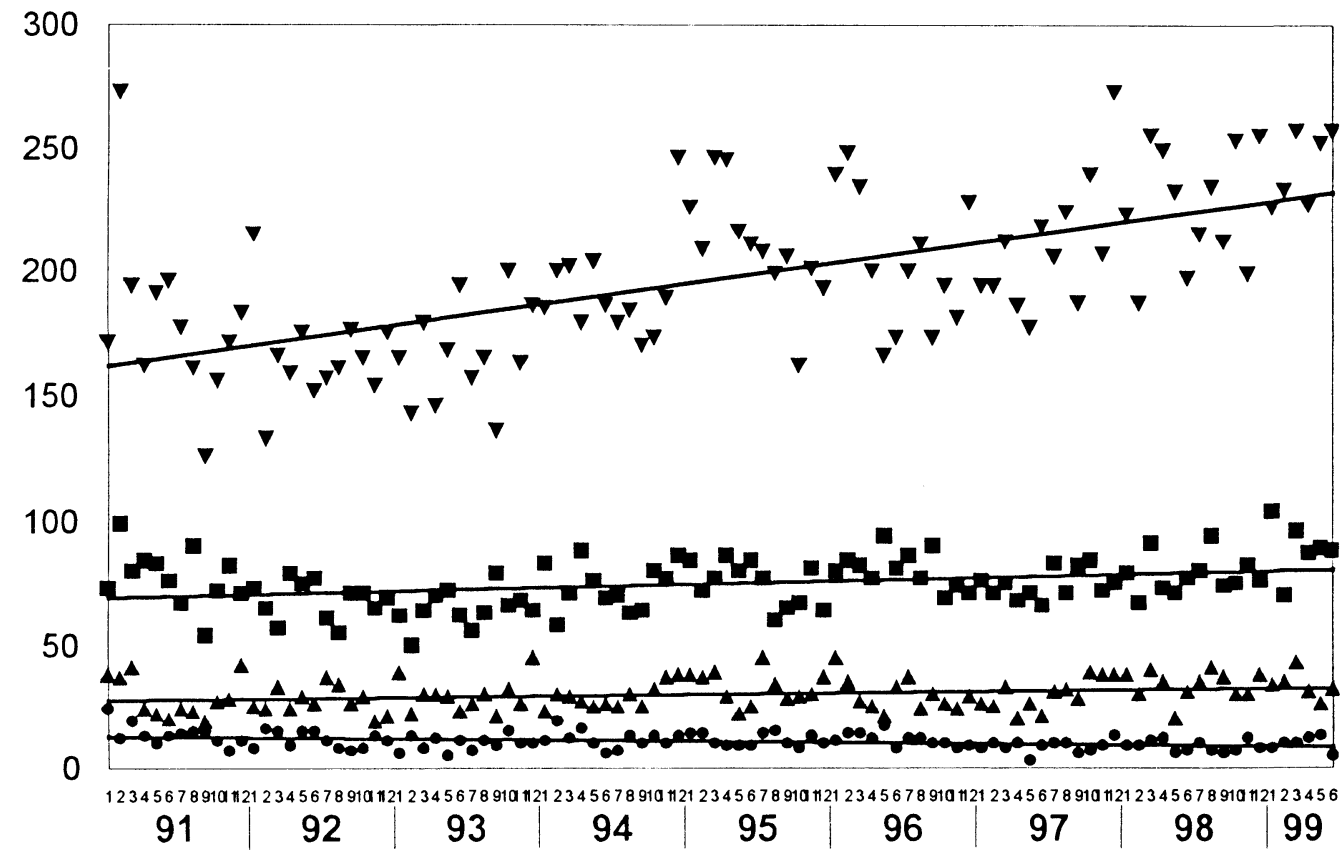

Fonte: PRO-AIM

$\rightarrow$ ah $1+$ ah $2 \rightarrow$ ah $3 \rightarrow$ ah 4

